Vol 11, Issue 9, 2018

\title{
PHARMACOVIGILANCE STUDY OF ANTIRETROVIRAL THERAPY IN HUMAN IMMUNODEFICIENCY VIRUS/ACQUIRED IMMUNODEFICIENCY SYNDROME PATIENTS AT ANTIRETROVIRAL THERAPY CENTRE, JABALPUR
}

\author{
RAJKUMARI BANSAL, DARYANI K K, AJIT PRATAP SINGH*
}

Department of Pharmacology, NSCB Medical College Jabalpur, Madhya Pradesh, India. Email: drajitsingh1978@gmail.com

Received: 17 April 2018, Revised and Accepted: 26 May 2018

\section{ABSTRACT}

Objective: The objective of the study was to assess the adverse drug reactions (ADRs) of antiretroviral therapy along with its causality, severity, and preventability.

Method: A prospective as well as a retrospective observational study with a sample size of 260, jointly conducted in the Department of Pharmacology and antiretroviral therapy (ART) center of N.S.C.B. Medical College Jabalpur, India, from March 2016 to July 2017. We observed various ADRs to ART in human immunodeficiency virus (HIV)/acquired immunodeficiency syndrome (AIDS) patients and assessed causality, severity, and preventability of the reported ADRs as per the standard scales.

Results: A total of 260 patients were enrolled of which 220 (84.6\%) patients developed a total of 425 ADRs. Maximum 51.7\% of ADRs were caused by TLE followed by $37 \%$ with ZLN regimen. Most common ADRs were dizziness 18.6\%, rashes $14.6 \%$, anemia 10.6\%, and vomiting 6.6\%. Dizziness and rashes are mainly caused by TLE and ZLN regimen, respectively. Management of ADRs with a change in the regimen was applied as an interventional tool in $40 \%$ of the patients. Causality assessment as per the WHO-UMC scale showed that $55.5 \%$ of ADR were probable and $45.5 \%$ were possible. $84.5 \%$ of ADR was not preventable, while $15.5 \%$ of ADRs were probably preventable. $38 \%$ of ADRs were mild, $56 \%$ were moderate, and $6 \%$ were severe in nature.

Conclusion: Antiretrovirals, however, the milestone for the treatment of HIV/AIDS have very high potential for developing ADRs. Hence, active pharmacovigilance is needed for not only safety of the patients but also compliance to the treatment which is necessary for optimal therapeutic outcomes and to improve quality of life.

Keywords: Pharmacovigilance, Adverse drug reaction, Antiretroviral therapy, Acquired immunodeficiency syndrome.

(C) 2018 The Authors. Published by Innovare Academic Sciences Pvt Ltd. This is an open access article under the CC BY license (http://creativecommons. org/licenses/by/4. 0/) DOI: http://dx.doi.org/10.22159/ajpcr.2018.v11i9.26747

\section{INTRODUCTION}

The word "pharmacovigilance (PV)" is derived from pharmakon (Greek: Drug) and vigilare (Latin: To keep watch) also known as drug safety, refers to the process of continuous monitoring for unwanted effects and other safety-related aspects of marketed drugs [1]. PV heavily focuses on adverse drug reactions (ADRs), which is defined by the WHO as "A response to a drug which is noxious and unintended, and which occurs at doses normally used in man for the prophylaxis, diagnosis, or therapy of disease, or for the modification of physiological function" [2]. The thalidomide disaster, detected in 1961, is a milestone in origin and further development of PV. The WHO started a program for international drug monitoring in 1968. The Uppsala Monitoring Centre (UMC) was established in 1978 to support the WHO Programme for International Drug Monitoring. At present, 134 countries are participating in the PV program which is centrally coordinated by the WHO with its collaborating centre in Uppsala, Sweden. The UMC (UMC, WHO) maintains the global ADR database which contains more than 12 million reports in the software "Vigibase," a web-based online system [3].

Monitoring of ADRs is especially important when treatment is being scaled up, such as antiretroviral therapy (ART) for the human immunodeficiency virus (HIV)/acquired immunodeficiency syndrome (AIDS) patients. Although ART is very effective, these drugs are highly toxic and are associated with various ADRs; therefore, many patients warrant withdrawal of the drugs or even discontinuation of treatment resulting in treatment failure. Hence, PV plays an important role in the management of treatment and ensuring safety in HIV patients [4].
AIDS is a global problem. It has now been reported from more than 190 countries around the world, and a pool of HIV infected persons in Africa and Asia is large and expanding. Since the start of the epidemic, an estimated 76.1 million people have become infected with HIV, and 35 million people have died of AIDS-related illnesses. In only 2016, 1 million people died from AIDS-related illnesses, and 1.8 million people became newly infected worldwide. According to the UNAIDS, about 36.7 million people were living with HIV globally by the end of 2016 . Among them, 19.5 million people have access to ART [5].

The world has committed to end the AIDS epidemic by 2030. UNAIDS recommends a Fast-Track approach to achieve the 90-90-90 treatment target by 2020 , whereby $90 \%$ of people living with HIV should know their HIV status, $90 \%$ of people who know their HIV-positive status are accessing treatment, and $90 \%$ of people on treatment have suppressed viral loads. Global consensus and leadership have driven greater investment of financial and human capital, and mounting clinical experience and research, improved treatment regimens and diagnostics and reductions in the price of medicines have created gains in efficiency and effectiveness [6].

In India, approximately 2.1 million people are living with HIV in 2016, which is estimated to be the third largest population of HIV affected people in the world. In 2016, HIV prevalence in India was estimated at $0.3 \%$, and 62,000 people died from AIDS-related illnesses. Estimated numbers of new HIV infections in 2016 were 80 thousand and 1 million people are on ART who are living with HIV. The number of people newly initiating ART in 2016 was 176969 [7]. 
Growing socioeconomic burden of the disease in India led to the inception of National AIDS Control Organization (NACO) in 1986 and subsequently in the formation of National AIDS Programme in 1987. ART became the keystone of National AIDS Programme [8].

ART involves a combination of at least three or more HIV medicines from at least two classes of antiretroviral agents called highly active ART refer to as Anti-HIV “cocktail," given to the patients every day. It can slow the disease progression by preventing the virus from multiplying and destroying the CD4 cells, thus decreases the amount of virus in an infected persons' blood (viral load) and restore the immune system [9].

There are mainly six major classes of antiretroviral agents:

1. Nucleoside or nucleotide reverse transcriptase inhibitors (NRTIs/ NtRTIs) - zidovudine, abacavir, didanosine, emtricitabine, lamivudine, stavudine, and tenofovir.

2. Non-nucleoside reverse transcriptase inhibitors - efavirenz and nevirapine.

3. Protease inhibitors - atazanavir, lopinavir, and ritonavir.

4. Integrase inhibitors - raltegravir.

5. Fusion inhibitors - enfuvirtide.

6. Chemokine receptor antagonists (CCR5 antagonists) - Maraviroc.

There is also a medicine called cobicistat which increases the action of antiretrovirals but does not have any effect on the virus itself. Each drug class disrupts different stages of viral life cycle [10]. The documented side effects of these drugs are: Zidovudine causes bone marrow suppression leading to anemia and neutropenia. Stavudine causes nausea, peripheral neuropathy, pancreatitis, and lipoatrophy. Nevirapine causes skin rash, Steven Johnson Syndrome (SJS) and hepatitis. Efavirenz causes skin rash in $10 \%$ of patients. Lamivudine has minimum toxicity. Most common adverse effects of lamivudine were diarrhea, malaise, fatigue, headache, and sleep disturbances [11]. In our study, we observed the various ADRs to ART in HIV/AIDS patients and assessed causality, severity, and preventability of the reported ADRs at ART center Netaji Subhash Chandra Bose Medical College, Jabalpur M.P.

\section{METHODS}

After approval from the Institutional Ethics Committee, the study was jointly conducted in the Department of Pharmacology and ART center of N.S.C.B. Medical College, Jabalpur (MP), from March 2016 to July 2017. It was a prospective as well as a retrospective observational study with a sample size of 260 . The participants had been offered to voluntarily participate in the study. They had given written informed consent before they were enrolled in the study.

\section{Inclusion Criteria}

The following criteria were included in this study:

1. Patients of any age of either sex.

2. Both new and old registered patients who were on ART.

3. Patients who gave written informed consent.

\section{Exclusion Criteria}

The following criteria were excluded from this study:

1. Patients who do not give informed consent for participation in the study.

2. Patients who were not able to recall or explain the symptoms of ADR.

3. Patients unable to respond to verbal questions.

Every enrolled patient who was already on ART and who has newly started the ART during this study period, were observed. These patients were provided with Informed Consent Form, and their consent for the study was documented. Details of the participants were kept confidential. Detailed history of the patient including demographic detail, past and present illness, and concurrent systemic illness, and drug history was taken along with detailed clinical examination when the patient came for follow-up visits to ART center. These informations were recorded on a pre-designed patient pro forma and correlated with prefilled patient treatment records (white card). Essential laboratory investigations such as complete blood counts, liver function tests, renal function tests, lipid profile, blood sugar tests, and CD4 count were done or recorded from prefilled patient treatment records.

All the ADRs were duly filled up in the suspected adverse drug reaction reporting form of Central Drugs Standard Control Organization by interviewing with patient or patients' caretaker and by reviewing prefilled patient treatment records. To establish the etiologic agents for ADR, attention was paid to the drug history, speculating the temporal correlation with the drug, duration of ADR, type of reaction, improvement in reaction on withdrawal of drug and recurrence of reaction on rechallenge if possible. These ADR was further assessed for its causality, preventability, and severity using WHO-UMC criteria [12], Modified Schumock and Thornton criteria [13], and Modified Hartwig and Siegel scale [14], respectively. The data were analyzed using SPSS 20. Appropriate univariate and bivariate statistical analysis was carried out using the student's $t$-test for the continuous variable (age) and twotailed Fisher exact test or Chi-square $\left(\chi^{2}\right)$ test for categorical variables. All means are expressed as mean \pm standard deviation and proportion in percentages. The critical levels of significance of the results were considered at 0.05 levels, i.e., $\mathrm{p}<0.05$ was considered significant.

\section{RESULTS}

A total of 260 patients were enrolled in our study in which $47.7 \%$ were males and 52.3\% females. Only 220 (84.6\%) patients developed ADRs among them $47.3 \%$ were males and $52.7 \%$ were females. A total of 425 ADRs were observed of which $41 \%$ occurred in males and $59 \%$ in females (Table 1). Majority $68.2 \%$ of the cases was observed in 21-40 years in ADR+ group followed by $22.3 \%$ in $41-60$ years in the same. The mean age of cases in ADR+ group was observed to be 34.06 $( \pm 11.12)$ years. Statistically, cases with ADR belonged to significantly higher $(\mathrm{p}<0.001)$ mean age (Table 2). $45 \%$ and $38.6 \%$ of patients who experience ADRs were on regimen TLE and ZLN, respectively. Maximum $51.7 \%$ of ADRs were caused by TLE followed by $37 \%$ with ZLN regimen (Table 3).

Table 1: Gender distribution

\begin{tabular}{llll}
\hline Gender & $\begin{array}{l}\text { Total } \\
\mathbf{n = 2 6 0 ( \% )}\end{array}$ & ADR+n = 220 (\%) & $\begin{array}{l}\text { Total ADRs } \\
\mathbf{n = 4 2 5}(\%)\end{array}$ \\
\hline Male & $124(47.7)$ & $104(47.3)$ & $174(41)$ \\
Female & $136(52.3)$ & $116(52.7)$ & $251(59)$ \\
\hline
\end{tabular}

$\chi^{2}=0.10 ; P>0.05$ at $1 \mathrm{df}$, ADRs: Adverse drug reactions

Table 2: Age distribution

\begin{tabular}{llll}
\hline Age (years) & $\begin{array}{l}\text { Total } \\
\mathbf{n = 2 6 0}(\%)\end{array}$ & ADR+n = 220 (\%) & $\begin{array}{l}\text { Total ADRs } \\
\mathbf{n = 4 2 5}(\%)\end{array}$ \\
\hline $0-20$ & $24(9.2)$ & $17(7.7)$ & $28(6.6)$ \\
$21-40$ & $179(69)$ & $150(68.2)$ & $298(70.1)$ \\
$41-60$ & $53(20.3)$ & $49(22.3)$ & $86(20.2)$ \\
$>60$ & $4(1.5)$ & $4(1.8)$ & $13(3.1)$ \\
Mean \pm SD & $33.09 \pm 11.236$ & $34.06 \pm 11.123$ & \\
\hline
\end{tabular}

$\mathrm{t}=3.33 ; \mathrm{P}<0.001$, ADRs: Adverse drug reactions

Table 3: Drug regimens and patients found with ADRs

\begin{tabular}{llll}
\hline Regimen & $\begin{array}{l}\text { Total patients } \\
\mathbf{n = 2 6 0}(\mathbf{\% )}\end{array}$ & $\begin{array}{l}\text { ADR (+) patients } \\
\mathbf{n = 2 2 0}(\mathbf{\% )}\end{array}$ & $\begin{array}{l}\text { Total ADRs } \\
\mathbf{n = 4 2 5} \mathbf{( \% )}\end{array}$ \\
\hline ALN & $8(3.1)$ & $7(3.2)$ & $8(1.9)$ \\
SLN & $21(8.1)$ & $17(7.7)$ & $22(5.2)$ \\
TLE & $121(46.5)$ & $99(45)$ & $220(51.7)$ \\
TLN & $8(3.1)$ & $7(3.2)$ & $10(2.3)$ \\
ZLE & $5(1.9)$ & $5(2.3)$ & $8(1.9)$ \\
ZLN & $97(37.3)$ & $85(38.6)$ & $157(37)$ \\
\hline
\end{tabular}


Most common ADRs were dizziness $18.6 \%$, rashes $14.6 \%$, anemia $10.6 \%$, and vomiting $6.6 \%$. Dizziness and rashes are mainly caused by TLE and ZLN, respectively. Nightmares $2.6 \%$ and renal toxicity $3.3 \%$ are found only in TLE. Lipodystrophy $1.4 \%$ occurred by SLN and TLE. Anemia $10.6 \%$ and neutropenia 3.3\% mainly occurred in ZLN. Excessive sweating $0.9 \%$ and hair fall $1.4 \%$ occurred in TLE and ZLN, respectively. Only 2 patients had SJS, in ZLN (Table 4).

Table 5 shows interventions taken after experiencing ADR by different regimens. $2.3 \%$ patients of SLN and $8.6 \%$ patients of ZLN were switched to SLE and ZLE regimen, respectively. 7.3\% patients were switch to SLN who were on ZLN regimen. $15 \%$ of patients were allowed to withhold the treatment. Thus, the change in the regimen was applied as an interventional tool in $40 \%$ of the patients to alleviate there ADRs.

Causality assessment as per the WHO-UMC causality scale shows that $98(44.5 \%)$ patients, among a total of 220 , had possible affiliation to the offending drug while 122 (55.5\%) patients had a probable association to the drugs (Table 6). Preventability assessment according to modified Schumock and Thornton scale shows that of 220 patients who were found to have ADRs in our study, 186 (84.5\%) patients would not be prevented while $34(15.5 \%)$ patients would probably be prevented (Table 7). Table 8 shows that majority of patients were categorized in to mild and moderate in terms of severity assessment of ADR's using modified Hartwig and Siegel scale.

\section{DISCUSSION}

A total of 260 patients were observed during the study period of 18 months. Patients developed ADRs with the incidence rate of $84.6 \%$. Sharma et al. [15] found the incidence rate of $71.1 \%$ which was less than ours whereas Nagpal et al. [16] reported that $90.64 \%$ patients experienced ADRs which were higher as compared to our study. Our study showed a higher prevalence of ADR in female (52.7\%) than male (47.3\%). Similar finding was also reported by Sadiq et al. [17], with a higher prevalence in female (64\%) as compared to male (36\%). In contrast, Khan et al. [18] reported a higher prevalence of ADRs in male $(74.8 \%)$ than female $(25.2 \%)$. The factors of the gender differences

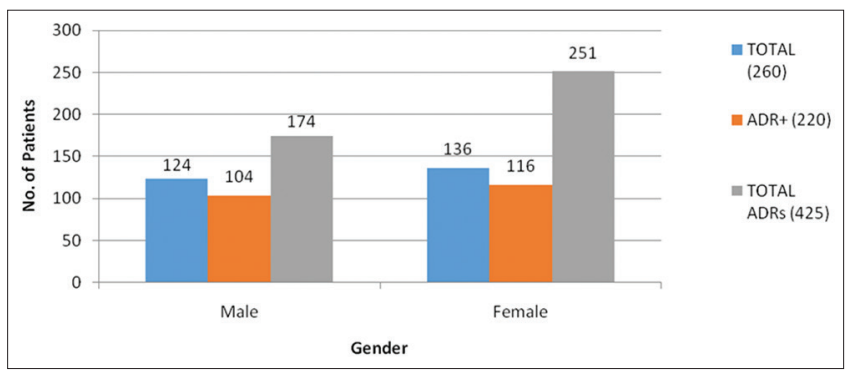

Fig. 1: Gender distribution

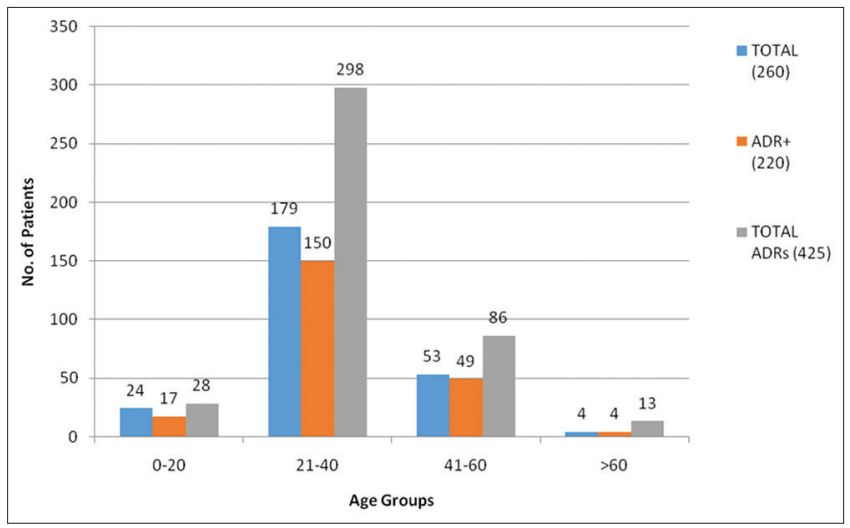

Fig. 2: Age distribution

Table 4: Various ADRs among different regimens

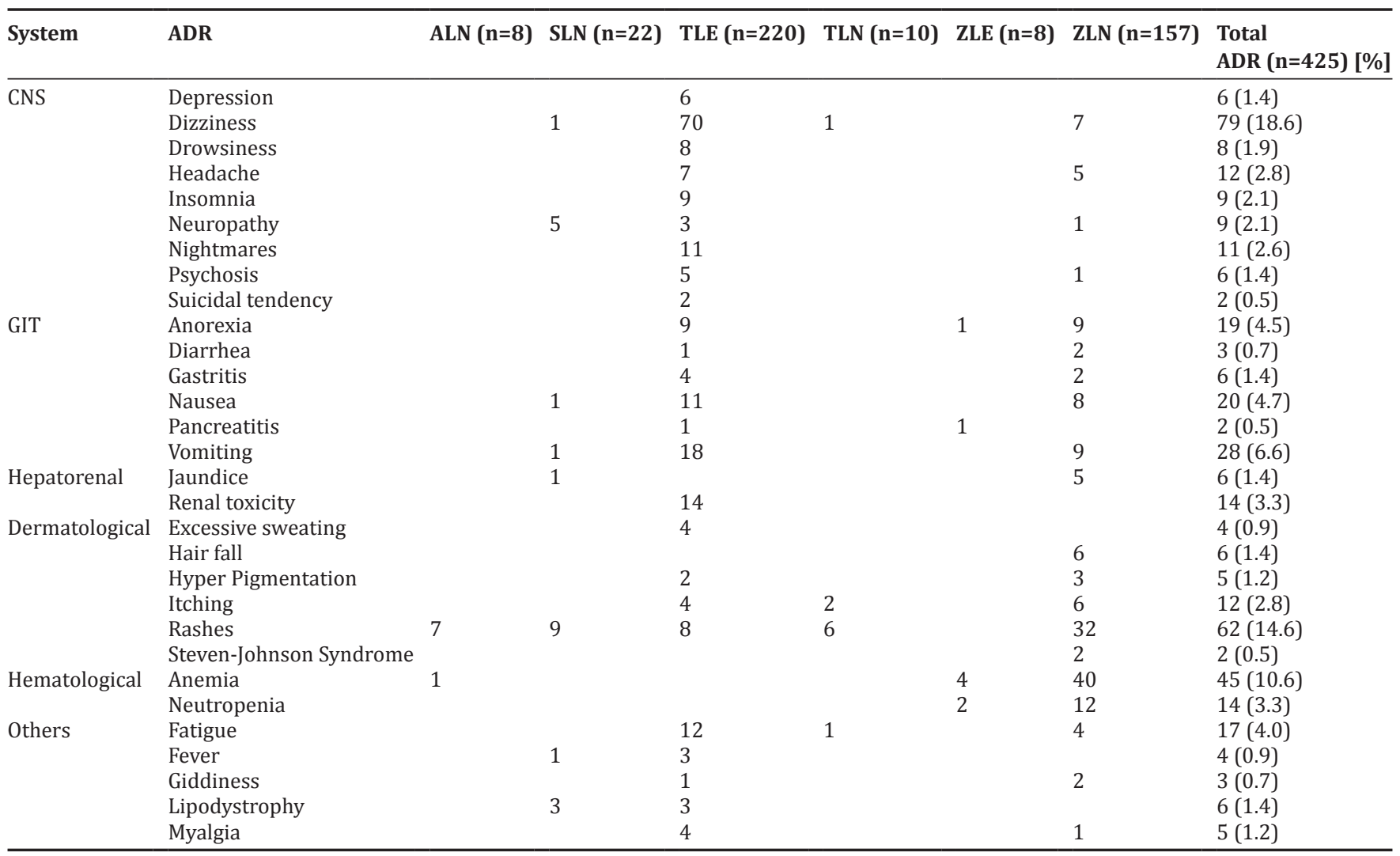

ADRs: Adverse drug reactions, CNS: Central nervous system 
Table 5: Interventions after ADRs

\begin{tabular}{|c|c|c|c|c|c|c|c|}
\hline \multirow[t]{2}{*}{ Interventions after ADRs } & \multicolumn{6}{|c|}{ Previous regimens } & \multirow[t]{2}{*}{ Total $n=220(\%)$} \\
\hline & $\operatorname{ALN}(n=7)$ & SLN (n=17) & TLE $(n=99)$ & $\operatorname{TLN}(n=7)$ & ZLE $(n=5)$ & ZLN (n=85) & \\
\hline Switch to SLE & & 5 & & & & & $5(2.3)$ \\
\hline Switch to SLN & & & & & & 16 & $16(7.3)$ \\
\hline Switch to TLE & 1 & 9 & & 6 & 3 & 29 & $48(21.8)$ \\
\hline Switch to ZLE & & & & & & 19 & $19(8.6)$ \\
\hline Counseling (Couns.) & & & 45 & 1 & & & $46(21)$ \\
\hline Counseling with Symp. t/t & & 1 & 40 & & & 12 & $53(24)$ \\
\hline Withhold & 6 & 2 & 14 & & 2 & 9 & $33(15)$ \\
\hline
\end{tabular}

ADRs: Adverse drug reactions

Table 6: Causality assessment

\begin{tabular}{ll}
\hline Causality assessment & Number of patients $\mathbf{n = 2 2 0}(\mathbf{\%})$ \\
\hline Possible & $98(44.5)$ \\
Probable & $122(55.5)$ \\
\hline
\end{tabular}

Table 7: Preventability assessment

\begin{tabular}{ll}
\hline Preventability assessment & Number of patients $\mathbf{n = 2 2 0}(\mathbf{\%})$ \\
\hline Not preventable & $186(84.5)$ \\
Probably preventable & $34(15.5)$ \\
\hline
\end{tabular}

Table 8: Severity assessment

\begin{tabular}{ll}
\hline Severity assessment & Number of patients $\mathbf{n = 2 2 0}(\%)$ \\
\hline Mild & $84(38)$ \\
Moderate & $123(56)$ \\
Severe & $13(6)$ \\
\hline
\end{tabular}

for the appearance of ADRs might be due to hormonal effects, drug metabolism, fat composition, body mass index, immunological status, environmental factor, or genetic constitutional differences at the level of various enzymes.

Majority of the patients (69\%) belong to the age group of 21-40 years followed by the group between ages 41 and 60 years $(20.3 \%)$. This is comparable to the study of Sehgal et al. [19] who found that a large number of patients (74.9\%) belongs to the same age group.

Of total 425 ADRs, $51.7 \%$ occurred in patients who were on TLE regimen, $37 \%$ in the patients on ZLN regimen and remaining by others regimens. This is in accordance with Kumar et al. [20] where maximum ADRs amounting to $49.23 \%$ and $23.85 \%$ were observed with patients on TLE and ZLN regimen, respectively.

Most common ADR observed was dizziness 18.6\%, rashes $14.6 \%$, anemia $10.6 \%$, vomiting $6.6 \%$, and nausea $4.7 \%$ in our study. Jain et al. [21] also found dizziness $22.6 \%$ to be the most common ADR. Similar findings were also observed by Sehgal et al. [19]where dizziness was the most common central nervous system (CNS) adverse effect while Singh et al. [22] found peripheral neuropathy (20.8\%) as the most common ADR in their study. Other CNS ADRs were headache $2.8 \%$, nightmares $2.6 \%$, insomnia $2.1 \%$, neuropathy $2.1 \%$, drowsiness $1.9 \%$, psychosis $1.4 \%$, depression $1.4 \%$, and suicidal tendencies $0.5 \%$ as observed in our study which is caused by TLE regimen except for neuropathy which occurred mainly due to SLN regimen. This is in concordance with the study of Nagpal et al. [16] and Reddy et al. [23]. We found that efavirenz is commonly associated with CNS ADRs as observed by Sehgal et al. [19] and Kumar et al. [20]. This is mainly because of the hydroxylation of efavirenz to 8-hydroxy efavirenz, through CYP2B6, which is the main metabolite causing CNS toxicity. Acute psychosis and suicidal tendency were reported as new ADRs in our study. One case of these was found

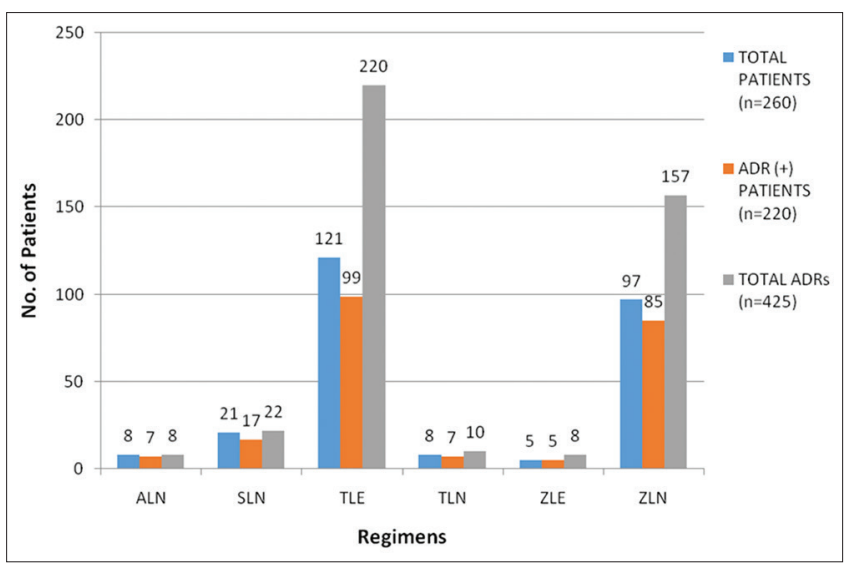

Fig. 3: Drug regimens and patients found with adverse drug reactions

to be as severely life-threatening, and remaining 5 were moderate in nature. It is very difficult to distinguish whether they are due to newly diagnosed disease origin or induced due to drug therapy. In such cases, we need psychiatric intervention. Mild to moderate cases of neuropathy were reported as tingling, numbness or paresthesia and in severe form permanent nerve damage due to stavudine-based regimens. We observed mild to moderate cases of neuropathy. As an intervention in peripheral neuropathy, we changed the regime and gave symptomatic treatment in the form of multivitamins. Newly started TLE causes dizziness as the most common side effect which subsided after 3-4 weeks with the regime being continued. The patient can be managed alone by counseling or assurance.

Vomiting 6.6\%, nausea $4.7 \%$, and anorexia $4.5 \%$ were the most common gastrointestinal ADRs followed by gastritis $1.4 \%$, diarrhea $0.7 \%$, and pancreatitis $0.5 \%$ in our study. $42.4 \%$ ADRs were gastrointestinal among all reported ADRs by Nagpal et al. [16] which comprised anorexia $24.8 \%$, gastritis $14.1 \%$, diarrhea $11.8 \%$, nausea $7.2 \%$, and vomiting 6.5\%. Khan et al. [18] observed pancreatitis 3.1\%, diarrhea $1.4 \%$, and vomiting $0.7 \%$ in their study. Sharma et al. [15] observed gastritis $10 \%$, anorexia $1.1 \%$, diarrhea $1.1 \%$, and pancreatitis $1.1 \%$ in their study. Reddy et al. [23] also reported the most common ADR in their study to be gastrointestinal with gastritis $13.13 \%$, anorexia $6.8 \%$, and nausea $2.5 \%$. In our study, most of GIT side effects are caused by TLE and ZLN regimen. This is in concordance with Kumari et al. [24] who found that maximum gastrointestinal ADRs occurred with TLE and ZLN regimen.

Nearly $1.4 \%$ of ADRs reported were jaundice and renal toxicity to be having an incidence of 3.3\%. Weldegebreal et al. [25]reported jaundice to be at $1.6 \%$ which was comparable to our study. Rather et al. [26] found renal toxicity (elevated serum creatinine) to be $3 \%$ which was also comparable to our study. Jaundice as nonspecific ADR can cause by all type of regimens but in our study mostly caused by ZLN and SLN (attributed to nevirapine) which appear in the form of the increased liver enzyme. In severe cases, elevated liver enzyme can rise to 5 times. 


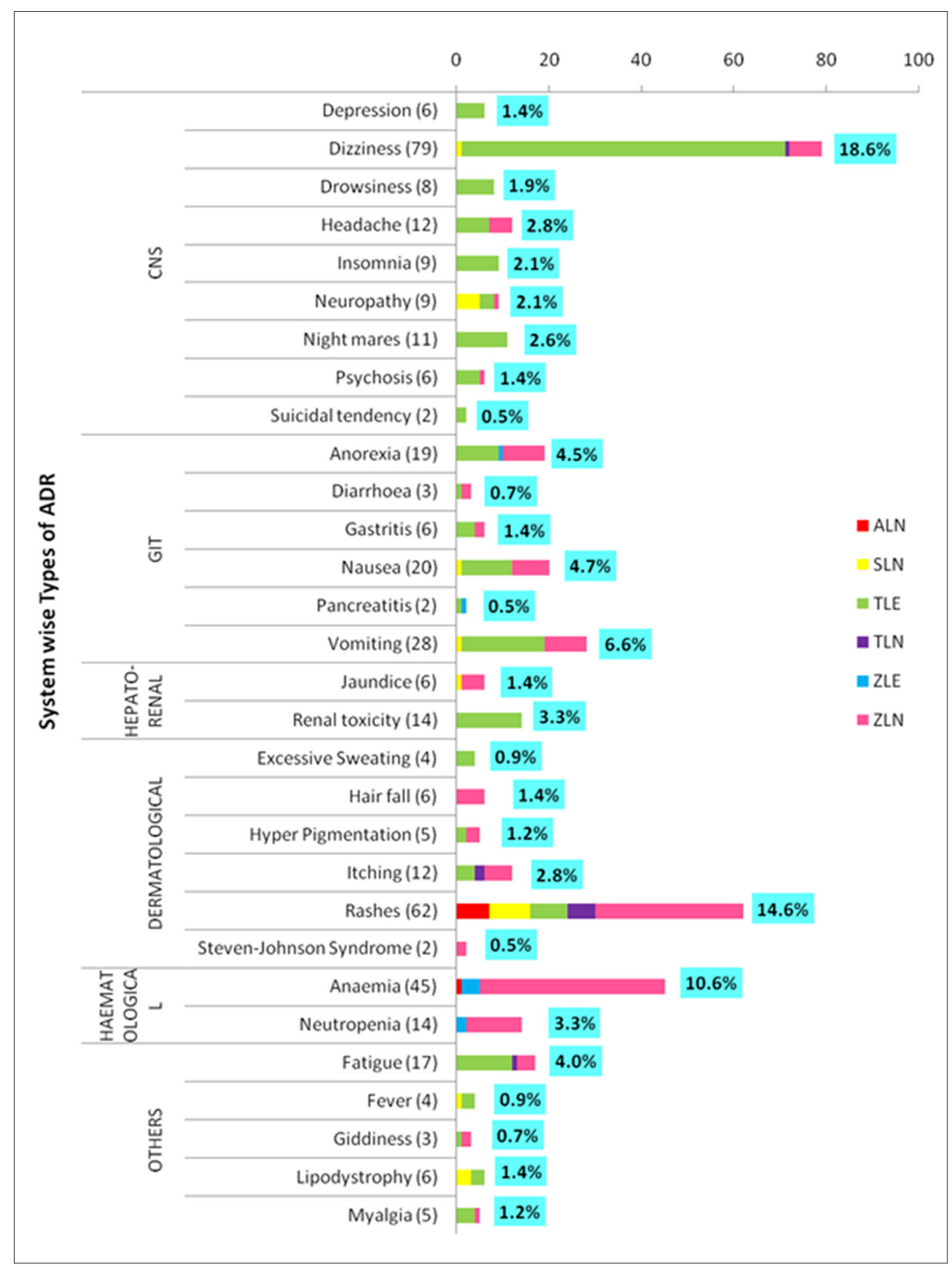

Fig. 4: Various adverse drug reactions among different regimens

Such cases want withholding the treatment until full recovery and restart an alternative therapy with close monitoring. Weldegebreal et al. [25] were in support of our observation where jaundice was caused by zidovudine-based regimen. Rather et al. [26] correlated hepatitis due to NRTIs which were also similar to our results. Renal toxicity was found mainly in TLE/tenofovir-based regimen which is concordance to Kumar et al. [20]. It is in the form of raised serum creatinine, increased uric acid or reduced creatinine clearance. When it occurs, therapy has to be withdrawn up to full recovery and adjustment of doses as per creatinine clearance.

It is a challenging task for the treating physician to distinguish whether the symptoms are due to the illness itself or through the drugs, however on withdrawing the drug if symptoms subside or resolve then it is in the favor of drug-induced reaction while if the symptoms worsen then it may be due to the illness itself.
Among dermatological reactions, rash $14.6 \%$, itching $2.8 \%$, hair fall $1.4 \%$, hyperpigmentation $1.2 \%$, excessive sweating $0.9 \%$, and SJS $0.5 \%$, were observed in our study. Masenyetse et al. [27] found the incidence of rash to be at $15 \%$ which is similar to our finding. Hyperpigmentation $14.4 \%$, itching $7.7 \%$, SJS $3.3 \%$, and hair loss $2.2 \%$ were found in the study by Sharma et al. [15] which is in support of our study. In our study, dermatological ADRs were mostly associated with ZLN regimen which is in concordance with Sharma et al. [15] and Reddy et al. [23] who also found that most of the cutaneous ADRs were due to ZLN regimen.

In our study, five cases of rashes were mild in nature and some of which are associated with itching. They occurred with the initiation of therapy and subsided after 1-2 weeks with symptomatic treatment. 20 cases were moderate to severe in nature which was managed by a change in the regimen and or withholding the treatment. Most of the rashes were maculopapular in type which is caused mainly by nevirapine, 


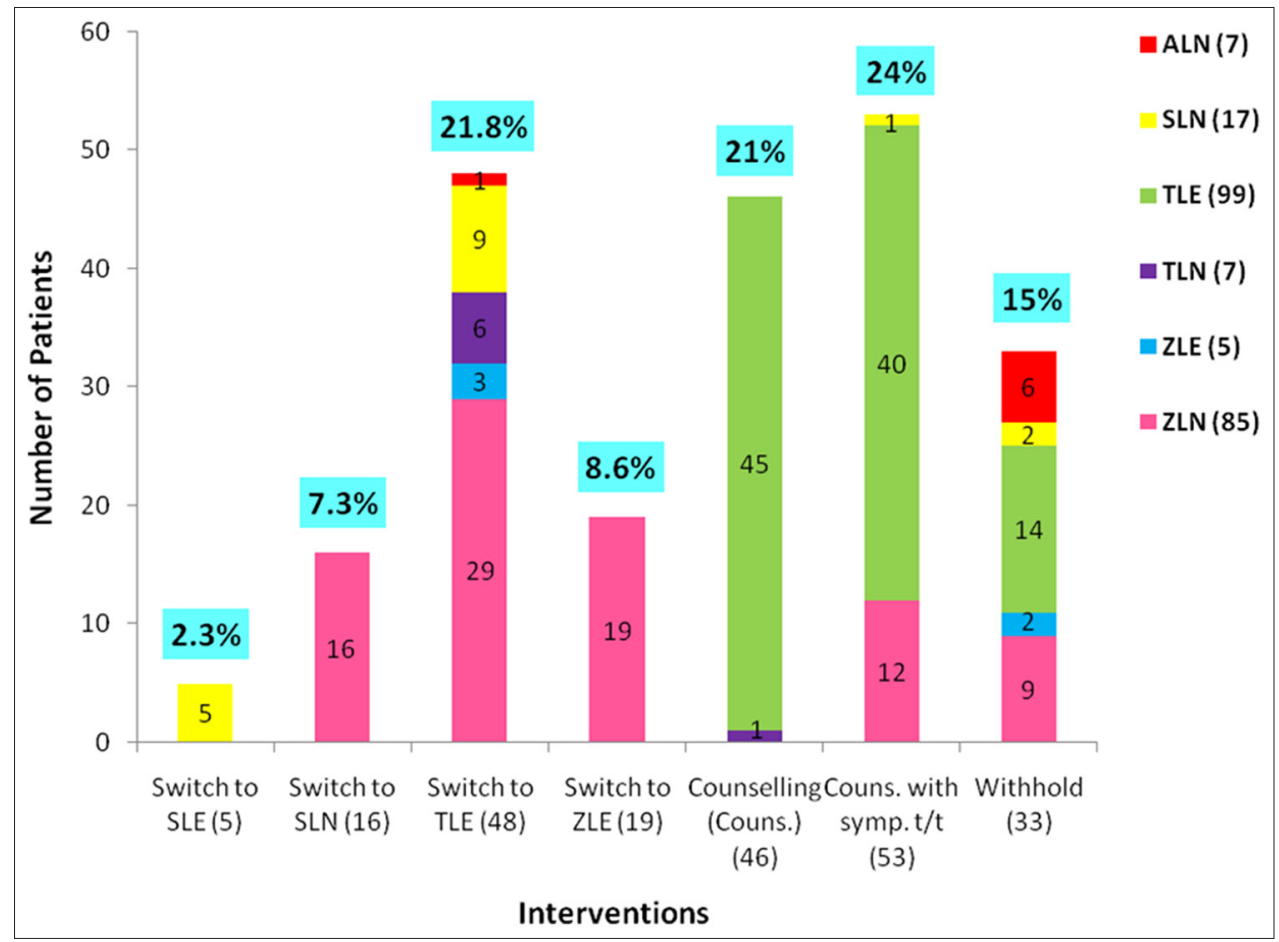

Fig. 5: Interventions after adverse drug reactions

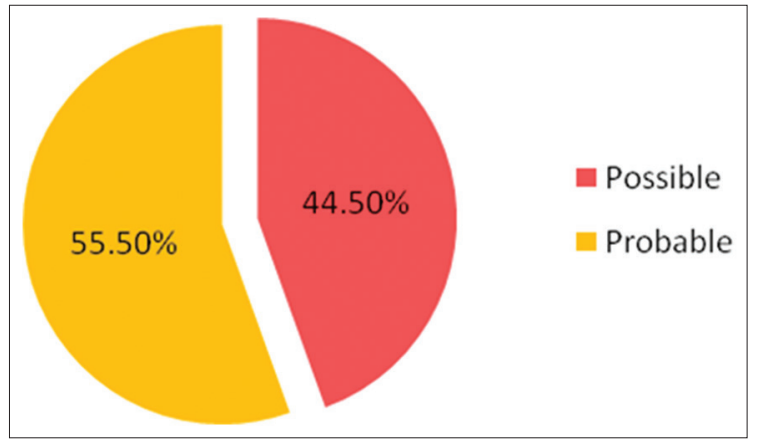

Fig. 6: Causality assessment

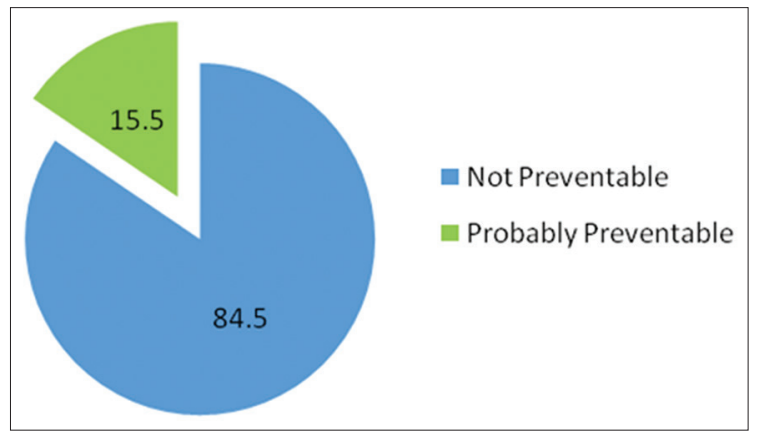

Fig. 7: Preventability assessment

Rather et al. [26] were too in concordance with our study who also found rashes to be caused by nevirapine while Weldegebreal et al. [25] observed skin rashes with zidovudine- and tenofovir-based regimen. Two cases of Steven-Johnson Syndrome were reported which required intensive care. It was very severe in form with generalized bulbous eruptions, mainly due to ZLN regimen and required withholding the therapy until full recovery and further switching to another therapy. Sharma et al. [15] and Reddy et al. [23] also showed the occurrence of rash to be caused by nevirapine-containing regimen.

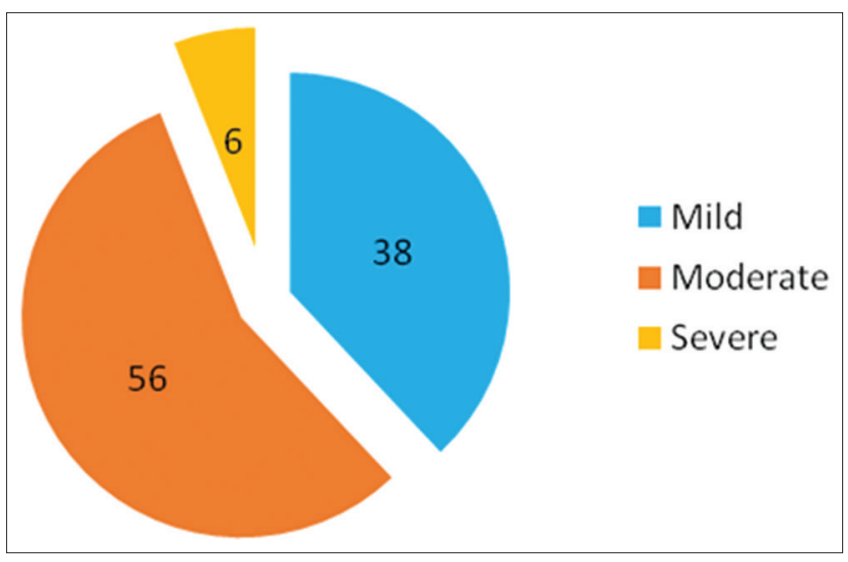

Fig. 8: Severity assessment

Hematological ADRs, mostly due to zidovudine-based regimen, were anemia $10.6 \%$ and neutropenia $3.3 \%$. Zidovudine causes bone marrow suppression which is the main factor for its causing anemia and neutropenia. Rather et al. [26] were too in supports to our study, where they observed anemia $58.6 \%$ and neutropenia $11.1 \%$ as the hematologic ADRs occurring with the zidovudine-based regimen. Three cases of severe anemia were reported with the hemoglobin of $<5 \mathrm{~g} \%$ and remaining cases under moderate anemia with the hemoglobin range of 6-8 g\%. Only three cases required withhold of treatment, and remaining were changed to another therapy with hematinics or blood transfusion. Abdissa et al. [28]are also in accordance to our study who found severe toxicities as anemia $32 \%$ and neutropenia $29.5 \%$ in their study.

Others ADRs such as fatigue $4 \%$, lipodystrophy $1.4 \%$, myalgia $1.2 \%$, fever $0.9 \%$, and giddiness $0.7 \%$ were also reported in our study. Sadiq et al. [17] and Reddy et al. [23] found similar types of ADRs in their studies.

Patients who experienced ADRs were managed by switching one drug or whole regimen (40\%). Patients who developed severe ADRs were 
allowed to withhold (15\%) the treatment until full recovery. Majority of mild to moderate cases of ADR were managed by counseling (21\%) and or symptomatic treatment (24\%). Our finding was similar to Luma et al. [29] where $68.2 \%$ patients needed the change in the regimen, and $31.8 \%$ were maintained on the same regimen with their ADRs subsided through symptomatic treatment. Abdissa et al. [28] showed that $10 \%$ of the patients required withhold of their therapy or change in treatment due to severe toxicity.

Causality assessment as per WHO-UMC scale showed that most of the ADR were probable $55.5 \%$ and $45.5 \%$ were possible. Kumari et al. [24] showed that $88 \%$ of ADRs were probable and $12 \%$ were possible while Anwikar et al. [30] found 96.4\% ADRs to be possible and 3.50\% probable. Kumar et al. [20] and Jain et al. [21] also found maximum ADRs to be possible. Rechallenge was not done in our cases because of associated risk and ethical reasons.

As per Modified Schumock and Thornton scale, most of the ADR were not preventable (84.5\%), while $15.5 \%$ of ADRs were probably preventable. Similar observation was seen by Kumari et al. [24] where the majority of ADRs (83.33\%) were not preventable, but Modayil et al. [31] found that $88 \%$ of ADRs were probably preventable which was contrary to our findings.

According to Modified Hartwig and Siegel severity assessment scale of ADRs, 84 (38\%) were mild, 123 (56\%) were moderate, and 13 (6\%) were severe in nature. Similar type of results was found by Anwikar et al. [30]where $8.77 \%, 77 \%$, and $14.02 \%$ ADRs were mild, moderate, and severe, respectively. These results are in contrast to Sadiq et al. [17] and Kumar et al. [20] where the majority of ADRs were mild followed by moderate and severe in nature.

\section{Limitations of study}

- Small sample size.

- Short duration of the study.

\section{CONCLUSION}

Antiretroviral although, the milestone for the treatment of HIV/AIDS has very high potential for developing ADRs which mainly affects the CNS, GIT, hematological, dermatological, and hepatorenal system. The TLE regimen prescribed as per the WHO and NACO guidelines cause mainly CNS ADRs, especially with efavirenz. These ADRs were mild to moderate in nature and subside spontaneously after 2-3 weeks without discontinuing the treatment. Maximum ADRs were managed by counseling and or symptomatically. Some drugs such as zidovudine and stavudine show ADRs such as anemia, neutropenia, and peripheral neuropathy after long-term treatment. Hence, active PV is needed for identification, prevention, and management of such ADRs developed by ART. This ensures not only the safety of the patients but also compliance to the treatment which is necessary for optimal therapeutic outcomes and to improve quality of life.

\section{AUTHOR'S CONTRIBUTION}

All the authors have contributed equally.

\section{CONFLICTS OF INTEREST}

The authors that they have none to declare.

\section{REFERENCES}

1. Pharmacovigilance. Internet Home Page. Available from: https://www. en.wikipedia.org/wiki/Pharmacovigilance.

2. World Health Organization. The Importance of PharmacovigilanceSafety Monitoring of Medicinal Products. Geneva: WHO; 2002. p. 40-43. Available from: http://www.apps.who.int/medicinedocs/pdf/ s4893e/s4893e.pdf.

3. “Uppsala Reports/72". WHO-Uppsala Monitoring Centre. 2016 April; Issue 72: Page 14. Available from: https://www.who-umc.org/ media/1237/uppsalareports-may-2016.pdf\#page $=14$.
4. Shah RR, Masatkar V, Bohra S, Malek N, Ghose G, Pandya HP. has HAART won heart of HIV/AIDS patients? World J Pharm Life Sci 2017:3:184-98.

5. UNAIDS. Fact Sheet July. 2017. Available from: http://www.unaids. org/sites/default/files/media_asset/UNAIDS_FactSheet_en.pdf.

6. UNAIDS. Global AIDS Update; 2016. Available from: http://www. unaids.org/sites/default/files/media_asset/global-AIDS-update-2016_ en.pdf.

7. UNAIDS AIDS info. Country Factsheets India; 2016. Available from: http://www.aidsinfo.unaids.org.

8. Bhuvana KB, Hema NG, Sangeetha. A prospective observational study of adverse drug reactions to antiretroviral therapy: Type and risk factors in a tertiary care teaching hospital. Int J Basic Clin Pharmacol 2014;3:380-4.

9. Kumar P. Sexually transmitted disease: Acquired immune deficiency syndrome: A review. J Appl Pharm Sci 2011;1:35-43.

10. HIV Medications-mTatva Health-PIE. Available from: https://www. mtatva.com/en/spl-health/hiv-medications/.

11. Rathod PS, Patil PT, Lohar RP, Patil AW Current trends in highly active antiretroviral therapy in an anti-retroviral therapy centre attached to a remote government medical college of Maharashtra, India: a retrospective study. Int J Basic Clin Pharmacol 2016;5:1011-6.

12. The use of the WHO-UMC System for Standardised Case Causality Assessment. Available from: https://www.who-umc.org/media/2768/ standardised-case-causality-assessment.pdf.

13. Schumock GT, Thornton JP. Focusing on the preventability of adverse drug reactions. Hosp Pharm 1992;27:538.

14. Hartwig SC, Siegel J, Schneider PJ. Preventability and severity assessment in reporting adverse drug reactions. Am J Health Syst Pharm 1992;49:2229-32

15. Sharma A, Vora R, Modi M, Sharma A, Marfatia Y. Adverse effects of antiretroviral treatment. Indian J Dermatol Venereol Leprol 2008;74:234-7

16. Nagpal M, Tayal V, Kumar S, Gupta U. Adverse drug reactions to antiretroviral therapy in AIDS patients at a tertiary care hospital in India: A prospective observational study. Indian J Med Sci 2010;64:245-52.

17. Sadiq S, Gupta S, Khajuria V, Tandon VR, Mahajan A, Gupta M. Adverse drug events due to antiretroviral therapy in a northern Indian tertiary care institution. Natl J Physiol Pharm Pharmacol 2016;6:205-8

18. Khan K, Khan AH, Sulaiman SA, Soo CT, Akhtar A. Adverse drug reactions in HIV/AIDS patients at a tertiary care hospital in Penang, Malaysia. Jpn J Infect Dis 2016;69:56-9.

19. Sehgal R, Gupta MC, Ghalaut PS. Adverse event monitoring of antiretroviral drugs - A pharmacovigilance perspective. Int J Pharmacol Res 2017;7:65-70

20. Kumar A, Majhee L, Gari M. Causality, severity and preventability assessment of adverse drug reactions in patients received anti-retroviral therapy in a tertiary care hospital: A retrospective study. Natl J Physiol Pharm Pharmacol 2017;7:178-82.

21. Jain A, Lihite RJ, Lahkar M, Baruah SK. A study on adverse drug reactions to first-line antiretroviral therapy in HIV infected patients at a tertiary care hospital in Northeast India. HIV AIDS Rev 2016;15:131-5.

22. Singh H, Dulhani N, Tiwari P, Singh P, Sinha T. A prospective, observational cohort study to elicit adverse effects of antiretroviral agents in a remote resource-restricted tribal population of Chhattisgarh. Indian J Pharmacol 2009;41:224-6.

23. Reddy AK, Lihite RJ, Lahkar M, Choudhury U, Baruah SK. A study on adverse drug reactions in HIV infected patients at a ART centre of tertiary care hospital in Guwahati, India. Asian J Pharm Clin Res 2013;6:102-4.

24. Kumari R, Chandra S, Gari M, Kumari A. An assessment of adverse drug reaction patterns among HIV positive patients receiving antiretroviral therapy in a tertiary care hospital. Int J Pharmacol Res 2017;7:88-93

25. Weldegebreal F, Mitiku H, Teklemariam Z. Magnitude of adverse drug reaction and associated factors among HIV-infected adults on antiretroviral therapy in Hiwot Fana specialized university hospital, Eastern Ethiopia. Pan Afr Med J 2016;24:255.

26. Rather ZA, Chowta MN, Raju GJ, Mubeen F. Evaluation of the adverse reactions of antiretroviral drug regimens in a tertiary care hospital. Indian J Pharmacol 2013;45:145-8.

27. Masenyetse LJ, Manda SO, Mwambi HG. An assessment of adverse drug reactions among HIV positive patients receiving antiretroviral treatment in South Africa. AIDS Res Ther 2015;12:6. 
28. Abdissa SG, Fekade D, Feleke Y, Seboxa T, Diro E. Adverse drug reactions associated with antiretroviral treatment among adult Ethiopian patients in a tertiary hospital. Ethiop Med J 2012;50:107-13.

29. Namme Luma $H$, Doualla MS, Choukem SP, Temfack E, Ashuntantang G, Achu Joko H, et al. Adverse drug reactions of highly active antiretroviral therapy (HAART) in HIV infected patients at the general hospital, Douala, Cameroon: A cross sectional study. Pan Afr Med J 2012;12:87.
30. Anwikar SR, Bandekar MS, Smrati B, Pazare AP, Tatke PA, Kshirsagar NA, et al. HAART induced adverse drug reactions: A retrospective analysis at a tertiary referral health care center in India. Int J Risk Saf Med 2011;23:163-9.

31. Modayil RR, Harugeri A, Parthasarathi G, Ramesh M, Prasad R, Naik V, et al. Adverse drug reactions to antiretroviral therapy (ART): An experience of spontaneous reporting and intensive monitoring from ART centre in India. Pharmacoepidemiol Drug Saf 2010;19:247-55. 